\title{
Development of Skills of Intercultural Communication in the Process of Studying at Higher Educational Institutions
}

\author{
Oksana V. Balanaieva ${ }^{1}$, Hanna M. Salashchenko은 Kateryna V. Shurupova ${ }^{2}$, Anastasiia O. Devos ${ }^{3} \&$ Alla I. \\ Romanchuk $^{4}$ \\ ${ }^{1}$ Department of Foreign Languages, Donetsk Law Institute of MIA of Ukraine, Kryvyi Rih, Ukraine \\ ${ }^{2}$ Department of Philosophy and Social Sciences, Faculty of Transport, Kryvyi Rih National University, Kryvyi Rih, \\ Ukraine \\ ${ }^{3}$ Department of Romance Philology and Comparative-Typological Linguistics, Institute of Philology, Borys \\ Grinchenko Kyiv University, Kyiv, Ukraine \\ ${ }^{4}$ Department of Pedagogy and Methods of Primary Education, Faculty of Pedagogy and Psychology, National \\ Pedagogical Drahomanov University, Kyiv, Ukraine \\ Correspondence: Anastasiia O. Devos, National Pedagogical Drahomanov University, 9 Pyrogova str., Kyiv, 01601, \\ Ukraine.
}

Received: June 10, 2020

Accepted: August 3, 2020

Online Published: August 7, 2020

doi:10.5430/ijhe.v9n7p243

URL: https://doi.org/10.5430/ijhe.v9n7p243

\begin{abstract}
The article proves that the need for the development of intercultural communication skills in the learning process is due to external causes of globalization and internal requirements of the modern ethnocultural situation in Ukraine, as well as the needs of pedagogical science, which takes into account global development trends: anthropocentrism, search for value orientations and new worldview, the need for acquisition of intercultural interaction skills that ensure competitiveness in the global community. According to the author, the skills of intercultural communication of future specialists are characterized by the integrity of formation of personal qualities and abilities, the ability to switch from one culture-specific code to another, taking into account their differences, flexibly vary communication strategies and tactics, maintain a positive attitude; choice of verbal and non-verbal means. In this regard, the author proposed the idea of using Web 2.0 in the formation of intercultural communication skills. Experimental application of a special method of working with educational Internet resources based on Web 2.0 technologies was tested in the Practical English academic course. It was found that the use of Web 2.0 in the development of intercultural communication skills in the process of studying at higher educational institutions opens up a wide range of opportunities for educational practice: the use of free electronic resources used for educational purposes; independent creation of network content; interpersonal interactions of the subjects of the educational process. To analyse the results obtained and objectively consider the dynamics of changes in the level of development of intercultural communication skills, control and measuring materials selected were the assignments of the Level 6 Certificate of General Language Proficiency (CAE Advanced) and a test to determine the level of development of learning strategies - the Strategy Inventory for Language Learning (SILL) Version 7.0. It was found that the use of educational Internet resources based on Web 2.0 technologies activates the professionally significant qualities of future specialists, the ability to carry out intercultural communication, expands the horizons of the worldview and the sphere of professional activity to the maximum possible extent, professional mobility, which is a condition and basis of professionalism and mastery. The proposed methods, techniques and technologies can be used regardless of the foreign language and have transnational significance.
\end{abstract}

Keywords: intercultural communication skills, higher educational institutions, educational internet resources, Web 2.0 technologies, future specialists, educational process

\section{Introduction}

Ukraine's integration into the world educational and information space is connected with the search for new ways of forming the personality of a modern specialist who is able to navigate freely in a multicultural world, understanding its values and meanings (Campbell, 2012; Kuo, 2018; Madrid, Baldwin \& Belbase, 2016), embodying them in a personal existential position and worthy examples of civilized behaviour in the process of interaction with 
representatives of other professional communities both in our country and internationally (Aba, 2015). In this regard, higher educational institutions face a set of problems and tasks, which include: the development of axiological attitudes of an individual through its enrichment with universal and national-specific values of their own and other cultures (Pshenychna, 2017); strengthening humanitarianism - the general cultural content of education, associated with a broad understanding of the phenomena of human life, polyphonic worldview and provides a harmony of knowledge, feelings, creative actions (Barker, 2016; Krok, 2015). It is necessary to expand the communicative range of future specialists based on interaction with representatives of other cultures and improve the quality of training based on integrative professional competencies (Thapa, 2020; Zholdasbekova \& Nurzhanbayeva, 2016).

These problems, refracting through the context of globalization and cultural dynamics, involve the formation of the modern specialists' ability to navigate in the global professional environment (Bennett, 2018). One of the means to achieve this goal is intercultural communication - the interaction of different cultures (Kosareva, Evreeva \& Zakirova, 2019; Szczurek-Boruta, 2015). The formation of intercultural communication skills as functional abilities to understand the views and opinions of the representatives of other cultures, correct their own behaviour, overcome conflicts in the communication process, recognize the right to different values, norms of behaviour (Byram, Holmes \& Savvides, 2013; Garson, 2016) is becoming most popular for modern specialists. They create a basis for professional mobility, preparation for rapidly changing living conditions, involve professionals in the standards of world achievements, increase opportunities for professional self-realization based on communication and tolerance (Liu, Volčic \& Gallois, 2015).

The result of the established teaching practice in higher educational institutions in the field of professionally oriented teaching of foreign languages is the fact that in the process of intercultural communication future professionals who are fluent in a foreign language have significant difficulties in understanding the meaning of foreign-language professional communication due to ignorance of norms and values inherent in the culture of another country (Aba, 2016; Berns, 2013; Kramsch, 2014), unformed multicultural worldview, personal behavioural qualities necessary for effective communication in the intercultural environment (Dai \& Chen, 2015).

A number of scholars (Adler \& Aycan, 2018; Confalonieri, Avezzù, Miano \& Veronese, 2016; Wereszczyńska, 2018; $\mathrm{Xu}, 2013)$ express the need to increase the effectiveness of intercultural communication skills by developing and implementing innovative technologies and methods of teaching in higher educational institutions to intensify the learning process and create an organizational and didactic basis for the implementation of the competency approach. Educational Internet resources based on Web 2.0 technologies have significant potential in eliminating these shortcomings.

Information and communication technologies of the Web 2.0 generation provide ample opportunities in foreign language learning, as they allow participants in the educational process to use ready-made Internet resources and become creators of their own Internet content (Garson, 2017). Web 2.0 technologies include podcasts, blogs, wikis, social networks, and other forms of organizing and transferring information. In Web 2.0 technologies, the determining factor is an individual, his social communications and individual preferences. Unlike the first-generation Internet, which is an environment for obtaining information, Web 2.0 technology become intermediaries between users in the process of their social interaction.

Web 2.0 technologies have formed four global spheres of influence, which are defined as learning, language literacy, collaboration, product demonstration. These areas concern both the cognitive (learning, language literacy) and social (collaboration, product demonstration) aspects of foreign language learning, and are seen as the process (learning and collaboration) and result (language literacy and product demonstration) of higher education.

Thus, the four presented aspects determine a number of opportunities for the introduction of Web 2.0 technologies in the educational process. Thanks to the huge capabilities of Web 2.0, the teachers can not only use ready Internet websites, but also create their own tasks for specific groups of students, for example, for a group project or research work, using such web formats as blog, wiki, podcast, flicker.

\subsection{Research Questions}

The objective of this study was to theoretically substantiate and experimentally prove that the development of intercultural communication skills during the study in higher educational institutions will be effective through the use of special methods of working with educational Internet resources based on Web 2.0 technologies.

\section{Materials and Methods}

The study has a prolonged nature, was conducted as an educational (organized in the educational process), test (used to test hypothetical provisions); horizontal (there were control and experimental groups); natural (conducted in the 
usual academic groups formed at the beginning of training); open (adjustments were made, the wording of assignments were changed during the experiment).

\subsection{Description of a Training Program}

Special methods of working with English-language educational Internet resources were based on the use of text, audio and visual materials, as well as social services Web 2.0 on various topics, and were aimed at developing intercultural communication skills. In total, seven formats of educational Internet resources were used: Hotlist, Multimedia Scrapbook, Treasure Hunt, Subject Sampler, Insight Reflector, Concept Builder, WebQuest. The nature of using Hotlist was based on displaying a grouped list of resources in English for text and multimedia. Multimedia Scrapbook displayed an annotated list of multimedia links on the topic (photos, maps, stories, facts, quotes, sound records, video clips). The use of Treasure Hunt involved students searching for information independently, step-by-step completion of assignments based on the use of Internet resources; Subject Sampler provided the study of a new topic through personal perception based on the ability to compare and interpret. In Insight Reflector, the main type of language activity was the letter, and the result of students' work was an essay based on the acquired knowledge, own emotions and experience. The Concept Builder format displayed a list of resources, analytical questions to identify topic concepts, and a final problem question. The peculiarity of using WebQuest was that some or all of the information for individual or group work of students is on different websites. In general, the formation of intercultural communication skills with the use of Web 2.0 educational Internet resources was based on a set of search and problem activities, which provided the normative use of verbal professionally-marked foreign language tools, variability of various communication strategies and cooperative communication tactics.

\subsection{Research Design}

This study was conducted at the Ivan Franko National University of Lviv with full-time students of the $2^{\text {nd }}-3^{\text {rd }}$ years of study based on the use of special methods of working with educational Internet resources based on Web 2.0 technologies while studying the subject Practical English Course. Its purpose was to intensify the educational process and the formation of intercultural communication skills of students. The $2^{\text {nd }}$-year students $(2$ subgroups $)$ and $3^{\text {rd }}$-year students ( 2 subgroups) participated in the study during the 2017-2019 academic years. In general, the experimental study was carried out in three stages: pre-experimental test, educational experiment itself, post-experimental test.

The experiment was conducted in the 2017-2019 academic year in two groups of 10-11 people each. The experimental verification of the levels of formation of intercultural communication skills included the level approach as the basic, according to which three levels were distinguished: high, medium, low. The assignments of the Certificate of Level 6 General Language Proficiency (CAE Advanced), developed at the University of Cambridge (Cambridge ESOL, 2006) and the test to determine the level of development of learning strategies (the Strategy Inventory for Language Learning (SILL)), Annex 3.4 of SILL (Version 7.0) (Ledwell \& Oyler, 2016), which belong to the type of structured questionnaires and are based on the system of strategies of Oxford (1990) were selected as control and measuring materials for pre-experimental and post-experimental tests.

Students received a maximum of 253 points for completing all parts of the Cambridge exam. The pre-experimental test allowed identifying three levels of intercultural communication skills formation according to the following parameters: high level - 80\%-100\% - 201 points and more; medium level - 60\%-79\% - 151-200 points; low level less than $60 \%-150$ points and less. Analysis of the results showed that the result in both groups is relatively low. The best result was 176 (EG-1) - 181 (CG-1) and 168 (EG-2) - 176 (CG-2), and the lowest 147 (EG-1) - 146 (CG-1) and 151 -2) - 150 (CG-2), thus, the average score in EG-1 - 163, EG-2 - 163; CG-1 - 166, CG-2 - 165.

\subsection{Formation of a Valid Sample of the Study}

At the beginning of the experiment, students were divided into 2 experimental (EG) and 2 control groups (CG). Conditions for experimental training were as follows: EG and CG had approximately the same sample size; the groups were homogeneous in terms of age; the same number of classes of the same intensity were delivered in the process of experimental training. Using the methods of mathematical statistics, it is proved that these groups can really be considered as EG and CG, which is determined by the Formula 1:

$$
\sqrt{n}=\frac{r}{\sigma}
$$

where $n$ - sufficient number of subjects for the experiment;

$r$-scope (the difference between the maximum and minimum results); 
$r=x_{i \max }-x_{i \min }$

$\sigma$ - standard deviation.

The following Formula 2 was used to calculate the standard deviation:

$$
\sigma=\sqrt{\frac{\sum\left(x_{i}-\bar{x}\right)^{2}}{n-1}}
$$

where $-x_{i}-$ the value of the sample, $\bar{x}-$ the sample average, $n-$ the sample size.

$\bar{x}=167 ; \quad r=30$.

The results of the first subgroup (EG-1) are shown in Table 1.

Table 1. Calculation of the standard deviation for EG-1

\begin{tabular}{cccc}
\hline Student & $x_{i}$ & $x_{i}-\bar{x}$ & $\left(x_{i}-\bar{x}\right)^{2}$ \\
\hline 1. & 169 & 2 & 4 \\
2 & 171 & 4 & 16 \\
3. & 166 & -1 & 1 \\
4. & 165 & -2 & 4 \\
5. & 168 & 1 & 1 \\
6. & 150 & -17 & 289 \\
7. & 150 & -17 & 289 \\
8. & 169 & 2 & 4 \\
9. & 178 & 11 & 121 \\
10. & 170 & 3 & 9 \\
11. & 180 & 13 & 169 \\
Sum: & 907 & & \\
\hline
\end{tabular}

$$
\sigma=\sqrt{\frac{907}{10}=9.52} ; \sqrt{n}=\frac{30}{9.52}=3.15 ; n=9.92 .
$$

The results of the first subgroup show that 10 students are enough to conduct the experiment. The results of the second subgroup (CG-1): $\bar{x}=170, r=35$ (Table 2).

Table 2. Calculation of the standard deviation for CG-1

\begin{tabular}{cccc}
\hline Student & $x_{i}$ & $x_{i}-\bar{x}$ & $\left(x_{i}-\bar{x}\right)^{2}$ \\
\hline 1. & 172 & 2 & 4 \\
2 & 174 & 4 & 16 \\
3. & 150 & 20 & 400 \\
4. & 175 & 5 & 25 \\
5. & 185 & 15 & 225 \\
6. & 180 & 10 & 100 \\
7. & 178 & 8 & 64 \\
8. & 156 & -14 & 196 \\
9. & 165 & -5 & 25 \\
10. & 160 & 10 & 100 \\
Sum: & 1155 & &
\end{tabular}




$$
\sigma=\sqrt{\frac{1155}{9}=11.32} ; \sqrt{n}=\frac{35}{11.32}=3.09 ; n=9.55 .
$$

The results of the second subgroup show that 10 students are enough to conduct the experiment. Calculation of the standard deviation for EG-2: $\bar{x}=167, r=17$ (Table 3).

Table 3. Calculation of the standard deviation for EG-2

\begin{tabular}{cccc}
\hline Student & $x_{i}$ & $x_{i}-\bar{x}$ & $\left(x_{i}-\bar{x}\right)^{2}$ \\
\hline 1. & 170 & 3 & 9 \\
2 & 171 & 4 & 16 \\
3. & 168 & 1 & 1 \\
4. & 170 & 3 & 9 \\
5. & 166 & 1 & 1 \\
6. & 156 & -11 & 121 \\
7. & 154 & -13 & 169 \\
8. & 171 & 4 & 16 \\
9. & 169 & 2 & 4 \\
10. & 170 & 3 & 9 \\
Sum: & 167 & & 355 \\
\hline & $\sigma=\sqrt{\frac{355}{9}=6.28 ;} \sqrt{n}=\frac{17}{6.28}=2.7 ; n=7.32$.
\end{tabular}

The results of EG-2 indicate that 7 students are enough to conduct the experiment. Let us consider the results of CG-2: $\bar{x}=169, r=25$ (Table 4).

Table 4. Calculation of the standard deviation for CG-2

\begin{tabular}{cccc}
\hline Student & $x_{i}$ & $x_{i}-\bar{x}$ & $\left(x_{i}-\bar{x}\right)^{2}$ \\
\hline 1. & 170 & 1 & 1 \\
2 & 173 & 4 & 16 \\
3. & 154 & -15 & 225 \\
4. & 173 & 4 & 16 \\
5. & 179 & 10 & 100 \\
6. & 179 & 10 & 100 \\
7. & 174 & 5 & 25 \\
8. & 156 & 13 & 169 \\
9. & 167 & 2 & 4 \\
10. & 160 & 9 & 81 \\
Sum: & 169 & & 737 \\
\hline & $\sigma=\sqrt{\frac{737}{9}=9.05 ;} \sqrt{n}=\frac{25}{9.05}=2.7 ; n=7.6$.
\end{tabular}

The results of CG-2 showed that 8 students were enough to conduct the experiment. Thus, the number of students in EG-1, EG-2 and CG-1, CG-2 allowed to use them in the experiment as EG and CG. However, the quantitative indicator of the subjects is not enough. It is necessary that there are no significant differences in quality characteristics between the groups. 
In such conditions, the main qualitative characteristic is the level of development of students' intercultural communication skills. For the experiment to be reliable, it is necessary that the subjects had approximately the same level of intercultural communication skills within the subgroup. To this end, a coefficient of variation was used to determine whether or not there were significant differences in the level of intercultural communication skills in each of the subgroups. The coefficient of variation is determined by the Formula 3:

$$
C_{x}=\frac{S_{x}}{\bar{x}} \times 100 \%
$$

where $C_{x}$ - a coefficient of variation, $S_{x}$ - the error of representativeness of the sample average (Formula 4$), \bar{x}$ - the sample average.

$$
S_{x}=\sqrt{\frac{\sum\left(x_{i}-\bar{x}\right)^{2}}{n(n-1)}}, \text { sample size } n=21
$$

Let us calculate the coefficient of variation in EG-1 and CG-1, where $\bar{x}=168.5$ (Table 5).

Table 5. Calculation of the coefficient of variation in EG-1 and CG-1

\begin{tabular}{cccc}
\hline Student & $x_{i}$ & $x_{i}-\bar{x}$ & $\left(x_{i}-\bar{x}\right)^{2}$ \\
\hline 1. & 169 & 0.5 & 0.25 \\
2 & 171 & 2.5 & 6.25 \\
3. & 166 & -2.5 & 6.25 \\
4. & 165 & -3.5 & 12.25 \\
5. & 168 & -0.5 & 0.25 \\
6. & 150 & -18.5 & 342.25 \\
7. & 150 & -18.5 & 342.25 \\
8. & 169 & 0.5 & 0.25 \\
9. & 178 & 9.5 & 90.25 \\
10. & 170 & 1.5 & 2.25 \\
11. & 180 & 11.5 & 132.25 \\
12. & 172 & 3.5 & 12.25 \\
13. & 174 & 5.5 & 30.25 \\
14. & 150 & -18.5 & 342.25 \\
15. & 175 & 6.5 & 42.25 \\
16. & 185 & 16.5 & 272.25 \\
17. & 180 & 11.5 & 132.25 \\
18. & 178 & 9.5 & 90.25 \\
19. & 156 & -12.5 & 156.25 \\
20. & 165 & -3.5 & 12.25 \\
21. & 160 & -8.5 & 72.25 \\
Sum: & & & 2007 \\
\hline & & &
\end{tabular}

$$
S_{x}=\sqrt{\frac{2007}{21 * 20}=2.19} ; C_{x}=\frac{2.19}{168.5} * 100 \%=1.3 \%
$$


The difference between the subjects for the said attribute is insignificant, if the coefficient of variation does not exceed 5\%. To increase the reliability of the experiment, sometimes this bar is reduced to $3 \%$. In our case, $1.3 \%<3 \%$, so the groups were really experimental.

Let us calculate the coefficient of variation inEG-2 andCG-2, where $\bar{x}=168, n=20$ (Table 6).

Table 6. Calculation of the coefficient of variation in EG-2 and CG-2

\begin{tabular}{cccc}
\hline Student & $x_{i}$ & $x_{i}-\bar{x}$ & $\left(x_{i}-\bar{x}\right)^{2}$ \\
\hline 1. & 170 & 1 & 1 \\
2 & 173 & 4 & 16 \\
3. & 154 & -15 & 225 \\
4. & 173 & 4 & 16 \\
5. & 179 & 10 & 100 \\
6. & 179 & 10 & 100 \\
7. & 174 & 5 & 25 \\
8. & 156 & 13 & 169 \\
9. & 167 & 2 & 4 \\
10. & 160 & 9 & 81 \\
11. & 170 & 3 & 9 \\
12. & 171 & 4 & 16 \\
13. & 168 & 1 & 1 \\
14. & 170 & 3 & 9 \\
15. & 166 & 1 & 1 \\
16. & 156 & -11 & 121 \\
17. & 154 & -13 & 169 \\
18. & 171 & 4 & 16 \\
19. & 169 & 2 & 4 \\
20. & 170 & 3 & 992 \\
Sum: & & & \\
\hline & & & 9 \\
\hline
\end{tabular}

$$
S_{x}=\sqrt{\frac{1092}{21 * 19}=2.87} ; C_{x}=\frac{2.87}{168} * 100 \%=1.7 \%
$$

In the study, $1.7 \%<3 \%$, so the groups were also experimental.

Analysis of the results of the pre-experimental test showed that students of EG and CG had an average level of intercultural interaction skills. This allowed us to assume that the EG students will be able to improve their intercultural interaction skills as a result of systematic work with educational Internet resources based on Web 2.0 technologies.

The second stage is an experiment itself, within which exercises for working with educational Internet resources based on Web 2.0 technologies for the formation of intercultural communication skills in students of the $2^{\text {nd }}-3^{\text {rd }}$ years of study were tested. A brief description of each educational Internet resource based on Web 2.0 technologies that correspond to the topic of the textbook is presented in Tables 7 and 8 . 
Table 7. Contents of developed educational Internet resources based on Web 2.0 technologies for the $2^{\text {nd }}$-year students

\begin{tabular}{|c|c|c|c|c|}
\hline $\begin{array}{l}\text { Item } \\
\text { No. }\end{array}$ & $\begin{array}{l}\text { Educational } \\
\text { situation }\end{array}$ & $\begin{array}{l}\text { Type of educational } \\
\text { Internet resources }\end{array}$ & $\begin{array}{l}\text { Web } 2.0 \\
\text { technology }\end{array}$ & Product \\
\hline \multicolumn{5}{|c|}{$2^{\text {nd }}$ year of study } \\
\hline 1. & $\begin{array}{l}\text { Choosing } \\
\text { a Career }\end{array}$ & Treasure Hunt, Hotlist & Blog, Wiki & $\begin{array}{l}\text { Report, interview, spreadsheet, } \\
\text { CV rules }\end{array}$ \\
\hline 2. & $\begin{array}{l}\text { Illnesses and } \\
\text { Treatment }\end{array}$ & $\begin{array}{l}\text { Treasure Hunt, Insight } \\
\text { Reflector }\end{array}$ & Blog, Wiki & Presentation, composition \\
\hline 3. & City & $\begin{array}{l}\text { Treasure Hunt, Hotlist, } \\
\text { WebQuest }\end{array}$ & $\begin{array}{l}\text { Blog, } \quad \text { Wiki, } \\
\text { Podcast, Flickr }\end{array}$ & $\begin{array}{l}\text { Photo-story, presentation, } \\
\text { announcement, reporting }\end{array}$ \\
\hline 4. & Meals & $\begin{array}{l}\text { Treasure } \\
\text { WebQuest }\end{array}$ & $\begin{array}{l}\text { Wiki, Podcast, } \\
\text { Flickr, Blog }\end{array}$ & $\begin{array}{l}\text { List of rules, } \\
\text { restaurant menu, hologue, } \\
\text { project }\end{array}$ \\
\hline 5. & Education & Hotlist, Insight Reflector & $\begin{array}{l}\text { Wiki, } \\
\text { Blog, }\end{array}$ & $\begin{array}{l}\text { Presentation, photo tour, } \\
\text { collage, composition }\end{array}$ \\
\hline 6. & $\begin{array}{l}\text { Sports and } \\
\text { Games }\end{array}$ & $\begin{array}{l}\text { Hotlist, Treasure Hunt, } \\
\text { WebQuest }\end{array}$ & $\begin{array}{l}\text { Wiki, Blog, } \\
\text { Podcast, Flickr, }\end{array}$ & $\begin{array}{l}\text { Table, dialogue, collage of } \\
\text { comments, reporting }\end{array}$ \\
\hline 7. & Geography & Treasure Hunt & Wiki & Announcement \\
\hline 8. & Travelling & Treasure Hunt & Wiki, Podcast & Announcement, dialogue \\
\hline 9. & Theatre & $\begin{array}{l}\text { WebQuest, } \\
\text { Treasure Hunt }\end{array}$ & $\begin{array}{l}\text { Wiki, Podcast, } \\
\text { Flickr, Blog }\end{array}$ & $\begin{array}{l}\text { Presentation, abstract, } \\
\text { composition, list of questions }\end{array}$ \\
\hline
\end{tabular}

Table 8. Contents of developed educational Internet resources based on Web 2.0 technologies for the $3^{\text {rd }}$-year students

\begin{tabular}{|c|c|c|c|c|c|c|}
\hline $\begin{array}{l}\text { Item } \\
\text { No. }\end{array}$ & $\begin{array}{l}\text { Educational } \\
\text { situation }\end{array}$ & \multicolumn{2}{|c|}{$\begin{array}{l}\text { Type of educational } \\
\text { Internet resources }\end{array}$} & $\begin{array}{r}\text { Web } 2 \\
\text { technolc }\end{array}$ & $\begin{array}{l}2.0 \\
\text { ogy }\end{array}$ & Product \\
\hline \multicolumn{7}{|c|}{$3^{\text {rd }}$ year of study } \\
\hline 1. & $\begin{array}{l}\text { Changing } \\
\text { Patterns of } \\
\text { Leisure }\end{array}$ & WebQuest & & $\begin{array}{l}\text { Blog, } \\
\text { Flickr }\end{array}$ & Wiki, & Picnic project \\
\hline 2. & $\begin{array}{l}\text { Man and } \\
\text { Movies }\end{array}$ & $\begin{array}{l}\text { Treasure } \\
\text { Hotlist }\end{array}$ & Hunt, & $\begin{array}{l}\text { Blog, } \\
\text { Podcast, } \\
\text { Youtube }\end{array}$ & Wiki, & $\begin{array}{l}\text { Composition, poster, } \\
\text { announcement, review, } \\
\text { presentation in } \\
\text { role-playing game }\end{array}$ \\
\hline 3. & $\begin{array}{l}\text { English } \\
\text { Schooling }\end{array}$ & $\begin{array}{l}\text { Hotlist, } \\
\text { Reflector }\end{array}$ & Insight & $\begin{array}{l}\text { Blog, } \\
\text { Flickr }\end{array}$ & Wiki, & $\begin{array}{l}\text { Composition, } \quad \text { draft } \\
\text { decisions, research report }\end{array}$ \\
\hline 4. & $\begin{array}{l}\text { Bringing Up } \\
\text { Children }\end{array}$ & $\begin{array}{l}\text { Insight Ref } \\
\text { Subject Sar }\end{array}$ & $\begin{array}{l}\text { ector, } \\
\text { pler }\end{array}$ & Wiki, Blog & & $\begin{array}{l}\text { Announcement, } \\
\text { composition }\end{array}$ \\
\hline 5. & Paintings & $\begin{array}{l}\text { Subject } \\
\text { Treasure } \\
\text { Concept Bu }\end{array}$ & $\begin{array}{l}\text { Sampler, } \\
\text { Hunt, } \\
\text { lder }\end{array}$ & $\begin{array}{l}\text { Wiki, } \quad F \\
\text { Blog, Podo }\end{array}$ & $\begin{array}{l}\text { Flickr, } \\
\text { cast }\end{array}$ & Composition, poster \\
\hline 6. & $\begin{array}{l}\text { Feelings and } \\
\text { Emotions }\end{array}$ & $\begin{array}{l}\text { Hotlist, } \\
\text { Reflector }\end{array}$ & Insight & $\begin{array}{l}\text { Wiki, } \\
\text { Flickr }\end{array}$ & Blog, & Album of emotions, poster \\
\hline 7. & $\begin{array}{l}\text { Talking about } \\
\text { People }\end{array}$ & WebQuest & & $\begin{array}{l}\text { Wiki, } \quad \text { I } \\
\text { Blog, Podo }\end{array}$ & $\begin{array}{l}\text { Flickr, } \\
\text { cast }\end{array}$ & Selection of a partner \\
\hline
\end{tabular}


The dominant format in the $2^{\text {nd }}$ year of study was Treasure Hunt and Hotlist, because on the one hand, students needed up-to-date factual information (Treasure Hunt), and on the other - it is necessary to develop cognitive skills in students. In the $3^{\text {rd }}$ year of study, the leading formats were Subject Sampler, Insight Reflector and WebQuest. These formats were higher in the level of complexity of the realization and development of intercultural communication skills. Educational Internet resources in the $3^{\text {rd }}$ year of study were aimed at analysis, transformation and interpretation of information.

In general, the study developed a set of exercises for the formation of intercultural communication skills using Web 2.0 technologies. The proposed system of exercises includes exercises for the development of individual skills and intercultural communicative competence in general: exercises entitled Identify, Describe, Name, Match, Record, Reproduce, Select, Translate, Give Examples, Convert, Predict, Report, Participate, Recognize, Discriminate, Limit, Categorize, Create, Conclude.

The presented system of exercises was based only on authentic materials. However, it was not enough to provide students with an authentic information resource, it was necessary to make the process of working on it authentic. This was possible only if the work on the text, audio or video file was perceived not as work on the exercise, but as an authentic communicative activity, which was created in the process of interaction of students with the resource, with each other, with the teacher. This eliminated the traditional opposition between the language used in-class and the real language of communication.

Below, we provide examples of educational Internet resources based on Web 2.0 technologies in the $2^{\text {nd }}$ year of study.

Unit 5 Education

Format: Hotlist

Title: Cambridge

Web 2.0 technologies: Blog, Wiki, Flicker, YouTube

Execution time: 90 minutes

Introduction

"Looking through the list of earlier Nobel laureates, I note a large number with whom I became acquainted and with whom I interacted during those years as they passed through Cambridge" John Pope

Assignment

Study these links and make a full presentation about University of Cambridge and its surroundings for: a) a historian or b) a tourist or c) a ESL student or d) a sportsman Links.

1. University of Cambridge - official site http://www.cam.ac.uk/

2. History of Cambridge - wiki page

-http://www.britainexpress.com/counties/cambridgeshire/az/cambridge/university-history.htm

3. Brief History of Cambridge - wiki page - http://www.colc.co.uk/cambridge/cambridge/history.htm

4. Cambridge and surroundings - http://www.visitcambridge.org/

5. Cambridge wiki page - http://en.wikipedia.org/wiki/Cambridge

6. Museums of Cambridge lists of museums - http://en.wikipedia.org/wiki/Cambridge_museums

7. Museums and Places to Visit - lists of places to visit - http://www.colc.co.uk/about/museums.html

8. Cambridge Online Newspaper - news - http://www.cambridge-news.co.uk/Home/

9. Cambridge University ESOL Examinations - official site - http://www.cambridgeesol.org/index.html

10. Gardens - map - http://www.botanic.cam.ac.uk/Botanic/Map.aspx

11. Route map - http://www.stagecoachbus.com/routemaps-cambridge.aspx

12. Walking Tour - http://walkit.com/cities/cambridge/ 


\section{Results}

The post-experimental test completed the educational experiment. The test tasks for the post-experimental test were the same as in the previous steps. The average score in EG-1 increased to 196 points (before the educational experiment -167 points), the growth of the same indicator in CG-1 is less significant and amounted to 181 points (before the educational experiment - 170 points). The average score in EG-2 increased to 202 points (before the educational experiment - 167 points), the growth of the same indicator in CG-2 was 179 points (before the educational experiment - 169points). This showed a significant difference between the results of EG and CG. The results show that in EG students with a low level of intercultural communication skills improved their results and moved to the group with medium indicators. Students with a high level of intercultural communication skills appeared in EG: they amount to 18\% in EG-1, in EG-2 - 30\%. Students with a high level of intercultural communication skills did not appear in the CG. The average result in EG was 14.5\% -15\% higher than CG values.

Statistical processing of the results to verify significant differences in the levels of formation of intercultural communication skills in students of CG and EG was carried out according to the U-199 Mann-Whitney test by the Formula 5:

$$
U_{\text {emp }}=\left(n_{1} \times n_{2}\right)+\frac{n_{x\left(n_{x+1}\right)}}{2}-T_{x}
$$

where $n_{1}$ - number of subjects in Sample1;

$n_{2}$ - number of subjects in Sample2;

$T_{x}$ - greater of the two rank sums;

$n_{x}$ - number of subjects in the group with a greater sum of ranks.

Let us compare the calculated rank sums EG-1 and CG-1 in the Table 9 of calculation of rank sums according to the samples of students.

Table 9. Comparison of the calculated rank sums EG-1 and CG-1

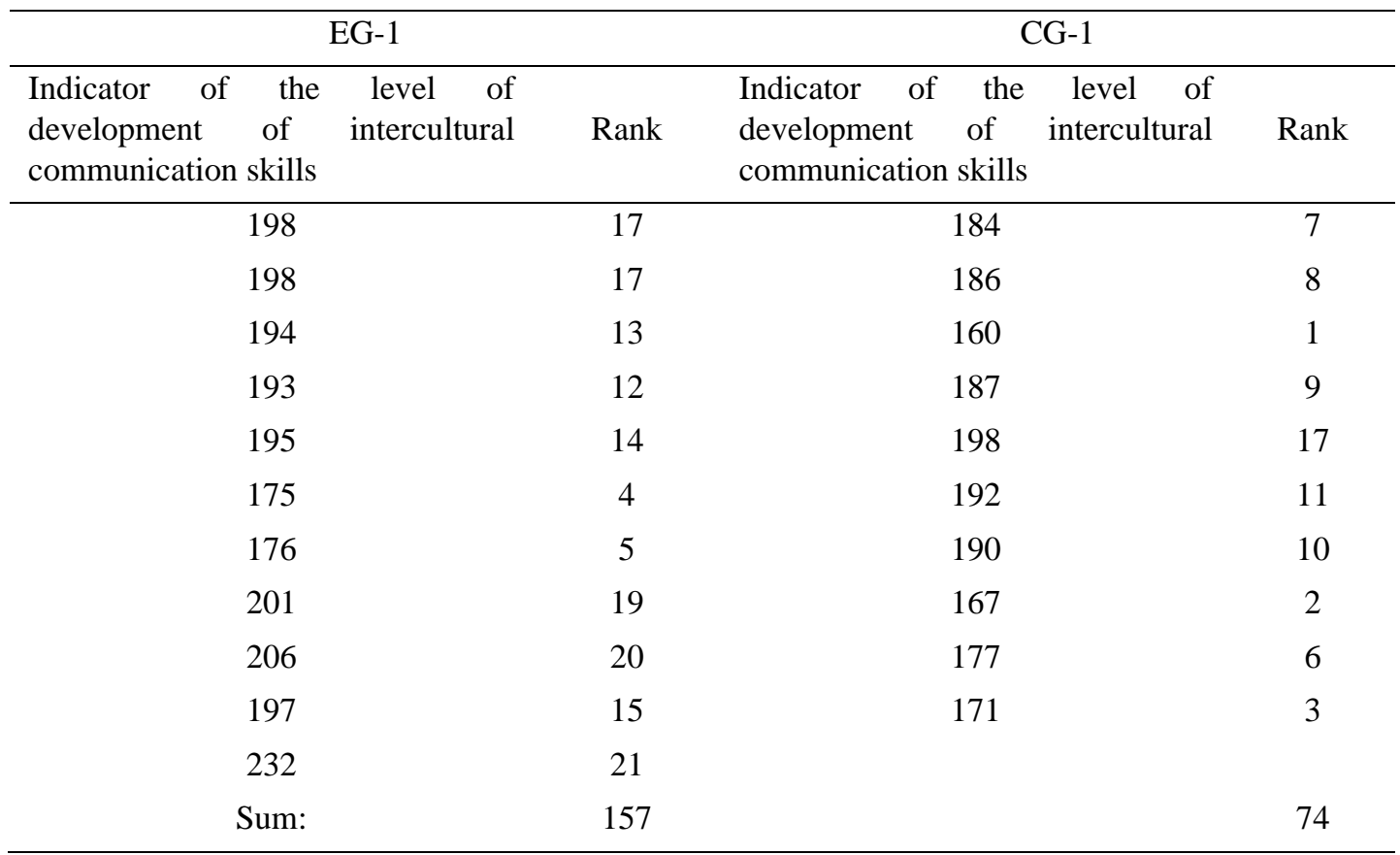

Next, the correctness of the rank calculations was verified: $157+74=231$.

Calculated sum by the Formula 6 (Liu et al., 2015):

$$
\sum R_{i}=\frac{N \times(N+1)}{2},
$$


where $N-$ the total number of ranked value

$$
\sum R_{i}=\frac{21 \times(21+1)}{2}=231
$$

Equality of real and calculated sum is observed. According to the level of development of intercultural communication skills, the sample of EG-1 was higher. It was this sample that accounted for a large rank sum: 157.

Then hypotheses were formed:

$H_{o}$ : EG-1 does not exceed CG-1 in terms of the level of the development of intercultural communication skills.

$H_{l}$ : EG-1 exceedsCG-1 in terms of the level of development of intercultural communication skills.

Let us determine the empirical value of $U$ by the Formula 7:

$$
\begin{aligned}
& U_{\text {emp }}=\left(n_{1} \times n_{2}\right)+\frac{n_{x\left(n_{x+1}\right)}}{2}-T_{x} \\
& U_{\text {emp }}=(11 * 10)+11(11+1) / 2-157=19
\end{aligned}
$$

According to of critical values of the Mann-Whitney U-test, the critical value for the corresponding $\mathrm{n}$ was determined. According to:

$$
\begin{aligned}
& U_{c r}=22(p \leq 0,01) \\
& U_{\text {emp }}<U_{c r}
\end{aligned}
$$

Thus, the hypothesis $H_{0}$ is rejected, and the hypothesis $H_{l}$ is accepted: EG-1 exceeds CG-1 in terms of the level of development of intercultural communication skills.

Let's compare the calculated rank sums EG-2 and CG-2 in the table of calculation of rank sums according to samples of students (Table 10).

Table 10. Comparison of the calculated rank sums EG-2 and CG-2

\begin{tabular}{cccc}
\hline \multicolumn{2}{c}{ EG-2 } & \multicolumn{2}{c}{ CG-2 } \\
\hline $\begin{array}{c}\text { Indicator of the level of development of } \\
\text { intercultural communication skills }\end{array}$ & Rank & $\begin{array}{l}\text { Indicator of the level of development } \\
\text { of intercultural communication skills }\end{array}$ & Rank \\
\hline 206 & 18 & 181 & 5 \\
205 & 16.5 & 182 & 6 \\
205 & 16.5 & 162 & 1 \\
204 & 15 & 187 & 8 \\
202 & 14 & 190 & 11 \\
191 & 12 & 188 & 9.5 \\
184 & 7 & 188 & 9.5 \\
209 & 19 & 166 & 2 \\
201 & 13 & 178 & 3 \\
215 & 20 & 168 & 5 \\
206 & 18 & & 59 \\
Sum: & 151 & & 3 \\
\hline
\end{tabular}

Next, the correctness of the rank calculations was verified: $151+59=210$.

The calculated sum (Liu et al., 2015): 


$$
\sum R_{i}=\frac{20 \times(20+1)}{2}=210
$$

Equality of real and calculated sum is observed. In terms of the level of intercultural communication skills, the EG-2 sample was "higher". It was this sample that accounted for a large ranking sum: 151.

The hypotheses were formed:

$H_{o}$ : EG-2 does not exceed CG-2 in terms of the level of development of intercultural communication skills.

$H_{I}$ : EG-2 exceeds CG-2 in terms of the level of development of intercultural communication skills.

Let us determine the empirical value of $U$ :

$$
U_{\text {emp }}=(10 * 10)+11(10+1) / 2-151=4
$$

According to of critical values of the Mann-Whitney U-test, the critical value for the corresponding $\mathrm{n}$ was determined. According to:

$$
\begin{aligned}
& U_{c r}=19(p \leq 0,01) \\
& U_{\text {emp }}<U_{c r}
\end{aligned}
$$

Thus, the hypothesis $\mathrm{H}_{\mathrm{o}}$ is rejected, and the hypothesis $H_{l}$ is accepted: EG-2 exceeds CG-2 in terms of the level of development of intercultural communication skills.

Numerical indicators confirmed the hypothesis of a relationship between the values of control and experimental samples and showed a positive dynamics of growth in the levels of intercultural communication skills of students. The effectiveness of the results is proved by statistical processing, which indicates the reasonability and effectiveness of the use of educational Internet resources based on Web 2.0 technologies in the development of intercultural communication skills in higher educational institutions.

\section{Discussion}

The study showed the effectiveness of the use of special methods of working with English-language educational Internet resources based on Web 2.0 technologies in the development of intercultural communication skills in the process of studying at higher educational institutions. Its use contributed to the analysis of students' English-language professional speech, identification of indirect ways of expressing negative content, the formation of active listening skills, strategies and tactics of professional communication, completion of assignments aimed at identifying the hidden content of utterance. EG students noted an increase in the professional orientation of an individual; expansion of the humanistic range of an individual on the basis of culturally-specific knowledge of foreign contexts, the ability to make moral choices in the system of value orientations; identification of tolerant behavioural reactions and cooperative communication style; increasing the foreign language range; deepening sensitivity to the national-language specifics of foreign language professional communication.

This study complemented and deepened the study of intercultural communication to support internationalization in higher education (French-Sloan, 2015; Lantz-Deaton, 2017; Vaccarino \& Mingsheng, 2018); acculturation and cross-cultural communication (Piller, 2017; Sam \& Berry, 2017; Safina, 2014; Savignon, 2017).

\section{Conclusion}

In the context of globalization of modern society, the development of intercultural communication skills in the process of studying in higher education is carried out on a broad qualitatively new professionally oriented general cultural basis, which is manifested in the choice of variable communication strategies and tactics in cooperation style based on specific national values and cultural universals in order to reach a compromise and consensus. Current Internet technologies for teaching foreign languages bring openness to the learning process, creating an open learning environment. Web 2.0 technologies allow students to join courses that have not been available to them so far; the assignments are always creative, and, most importantly, allow them to develop skills of intercultural communication in real time, in a real language situation. Thus, Web 2.0 technologies can be considered a kind of tool that effectively helps teachers to ensure publicity, nonlinearity, effectively helps teachers to deliver material, allows making changes to published material, provides the opportunity to moderate, comment, create a personal area. 
Students have the opportunity to study real conflict situations of intercultural communication, language and behaviour of participants of intercultural communication, to analyse and compare cultural differences in the rules of foreign language. It can be argued that the use of special methods of working with English-language educational Internet resources based on Web 2.0 technologies provides dialogism, reflexivity, multiculturalism, consideration of the emotional component and the integrity of personal development of students.

We see detailing and clarifying the content of intercultural communication skills in particular specialties and the use of educational Internet resources based on Web 2.0 technologies among the student audience and in the system of professional development, in the activities of organizations related to intercultural and interethnic communication both in our country and abroad as the directions for further research.

\section{Limitations and Implications for the Research}

The results of the study can be challenged, as the experiment was an experience for one higher educational institution with a limited number of respondents. The quasi-experimental design of the study and a number of variables studied were also limitations of this study.

This study predicts and experimentally proves that university-based Web 2.0 technologies should soon become the basis of modern education.

\section{References}

Aba, D. (2015). Towards an intercultural communication competence tool for academic mobility purposes. Journal of Intercultural Communication, 39, 451-474.

Aba, D. (2016). Addressing intercultural experience and academic mobility in higher education. Journal of Cross-Cultural Communication Research, 45(6), 487-502. https://doi.org/10.1080/17475759.2016.1236032

Adler, N. J. \& Aycan, Z. (2018). Cross-cultural interaction: What we know and what we need to know. Annual Review of Organizational Psychology and Organizational Behavior, 5, 307-333. https://doi.org/10.1146/annurev-orgpsych-032117-104528

Barker, G. G. (2016). Cross-cultural perspectives on cross-cultural communication competence. Journal of Cross-Cultural Communication Research, 45(1), 13-30. https://doi.org/10.1080/17475759.2015.1104376

Bennett, M. (2018). Basic concepts of intercultural communication: Paradigms, principles, \& practices. Boston, MA: Intercultural Press.

Berns, M. (2013). Context of competence: Social and cultural consideration in communicative language teaching. New York, NY: Springer Science \& Business Media.

Byram, M., Holmes, P., \& Savvides, N. (2013). Intercultural communicative competence in foreign language education: Questions of theory, practice and research. The Language Learning Journal, 41(3), 251-253. https://doi.org/10.1080/09571736.2013.836343

Cambridge ESOL. (2006). Cambridge certificate in advanced English 1 for updated exam student's book with answers: Official examination papers from University of Cambridge ESOL examinations. Cambridge, UK: Cambridge University Press.

Campbell, N. (2012). Promoting intercultural contact on campus: A project to connect and engage international and host students. Journal of Studies in International Education, 16(3), 205-227. https://doi.org/10.1177/1028315311403936

Confalonieri, A. M., Avezzù, C., Miano, S., \& Veronese, V. (2016). International quality mobility: Validation of the intercultural experience in terms of soft skills and enhanced employability. Journal of International Mobility, 4(1), 129-148. https://doi.org/10.3917/jim.004.0129

Dai, X., \& Chen, G. M. (2015). On interculturality and intercultural communication competence. China Media Research, 11(3), 100-114.

French-Sloan, H. (2015). Examining cross-cultural communication among first-year students at a large, four-year, research university. Lincoln, NE: University of Nebraska.

Garson, K. (2016). Reframing internationalization. Canadian Journal of Higher Education, 46(2), 19-39.

Garson, K. (2017). Internationalization and intercultural learning: Amixed methods study. In G. M. Gassia-Perez, \& C. Rojas-Primus (Eds.), Promoting Intercultural Communication Competencies in Higher Education, 54-88. Hershey, PA: IGI Global. https://doi.org/10.4018/978-1-5225-1732-0.ch003 
Kosareva, L., Evreeva, O., \& Zakirova, O. (2019). Formation of language competence: Modern issues and strategies in the area of cross-cultural communication. Space and Culture, India, 7(3), 149-159. https://doi.org/10.20896/saci.v7i3.525

Kramsch, C. (2014). Teaching foreign languages in an era of globalization: Introduction. The Modern Language Journal, 98(1), 296-311. https://doi.org/10.1111/j.1540-4781.2014.12057.x

Krok, D. (2015). The role of meaning in life within the relations of religious coping and psychological well-being. Journal of Religion and Health, 54(6), 2292-2308. https://doi.org/10.1007/s10943-014-9983-3

Kuo, T. S. (2018). Cross cultural management in the higher educational institutions. In W. R. Murhadi, D. Anandya, \& E, Andajani (Eds.), Proceedings of the 15th international symposium on management (INSYMA 2018): Advances in social science, education and humanities research (ASSEHR), 186, 6-9. New York, NY: Curran Associates, Inc.

Lantz-Deaton, C. (2017). Internationalisation and the development of students' intercultural competence. Teaching in Higher Education, 22(5), 532-550. https://doi.org/10.1080/13562517.2016.1273209

Ledwell, K., \& Oyler, C. (2016). Unstandardized responses to a "standardized" test: The edTPA as gatekeeper and curriculum change agent. Journal of Teacher Education, 67(2), 120-134. https://doi.org/10.1177/0022487115624739

Liu, S., Volčic, Z., \& Gallois, C. (2015). Introducing intercultural communication. Global cultures and contexts (2nd ed.). Thousand Oaks, CA: Sage.

Madrid, S., Baldwin, N., \& Belbase, S. (2016). Feeling culture: The emotional experience of six early childhood educators while teaching in a cross-cultural context. Global Studies of Childhood, 6(3), 336-351. https://doi.org/10.1177/2043610616664622

Oxford, R. L. (1990). Language learning strategies: What every teacher should know. Boston, MA: Heinle \& Heinle Publishers.

Piller, I. (2017). Cross-cultural communication: A critical introduction. Edinburgh, UK: Edinburgh University Press.

Pshenychna, L. (2017). Ensuring quality of higher education in the context of implementation of law of Ukraine "On higher education". Pedagogical sciences: theory, history, innovative technologies, 2, 113-129.

Safina, M. S. (2014). Formation of socio-cultural competence in foreign language teaching. Procedia - Social and Behavioral Sciences, 136, 80-83. https://doi.org/10.1016/j.sbspro.2014.05.292

Sam, D. L., \& Berry, J. W. (2017). Acculturation: When individuals and groups of different cultural backgrounds meet. Perspectives on Psychological Science, 5(4), 472-481. https://doi.org/10.1177/1745691610373075

Savignon, S. J. (2017). Communicative competence. New Haven, CT: Yale University Press. https://doi.org/10.1002/9781118784235.eelt0047

Szczurek-Boruta, A. (2015). Transformations of teacher training in the context of multiculturalism and euro-integration. Ruch Pedagogiczny, 1, 65-79.

Thapa, S. (2020). Assessing intercultural competence in teacher education: A missing link. In H. Westerlund, S. Karlsen \& H. Partti (Eds.), Visions for Intercultural Music Teacher Education. Landscapes: The Arts, Aesthetics, and Education (pp. 163-176). Cham, Switzerland: Springer. https://doi.org/10.1007/978-3-030-21029-8_11

Vaccarino, F., \& Mingsheng, L. (2018). Intercultural communication training to support internationalisation in higher education. Journal of Intercultural Communication, 46, 540-563.

Wereszczyńska, K. (2018). Importance of and need for intercultural education according to students: Future teachers. Polish Journal of educational studies, 72(1), 212-228. https://doi.org/10.2478/poljes-2018-0017

$\mathrm{Xu}, \mathrm{K}$. (2013). Theorizing difference in cross-cultural communication: A critical dialogic perspective. Communication Monographs, 80(3), 379-397. https://doi.org/10.1080/03637751.2013.788250

Zholdasbekova, S., \& Nurzhanbayeva, Zh. (2016). The conceptual model of future teachers training to dual education in VET (Vocational education \& training). International Journal of Environmental \& Science Education, 11(7), 1527-1538. 